\title{
NARRATIVAS DE ALFABETIZADORAS SOBRE CONTRIBUIÇÕES DA FORMAÇÃO DO PNAIC AO PROCESSO DE ENSINO E APRENDIZAGEM DE MATEMÁTICA EM UMA ESCOLA PÚBLICA MUNICIPAL DE PALMAS, TOCANTINS
}

\author{
NARRATIVES OF LITERACY TEACHERS ABOUT CONTRIBUTIONS OF PNAIC \\ FORMATION TO THE PROCESS OF TEACHING AND LEARNING OF \\ MATHEMATICS IN A PUBLIC MUNICIPAL SCHOOL FROM PALMAS, \\ TOCANTINS
}

Idemar Vizolli ${ }^{1}$

ORCID iD: $\underline{0000-0002-7341-7099}$

Seila Alves Pugas ${ }^{2}$

ORCID iD: $\underline{0000-0002-6515-4436}$

\begin{abstract}
RESUMO
Este artigo é um recorte de uma pesquisa mais ampla e tem como cujo objetivo verificar as contribuições do Pacto Nacional pela Alfabetização na Idade Certa (PNAIC) ao processo de ensino e aprendizagem de matemática no ciclo de alfabetização na Escola de Tempo Integral Padre Josimo Morais Tavares, Palmas, TO. Trata-se de uma pesquisa de natureza qualitativa, realizada por meio de entrevistas semiestruturadas com a supervisora escolar, a orientadora de estudos e com quatro professoras alfabetizadoras que participaram na formação continuada do PNAIC, e observações em sala de aula. Os resultados indicam que a formação do PNAIC forneceu contribuições significativas para a prática docente, principalmente em relação ao uso de metodologias diferenciadas para o ensino dos conteúdos, como o uso de jogos educativos e de sequências didáticas, além da ruptura com o modelo tradicional de avaliação.
\end{abstract}

Palavras-chave: PNAIC. Ensino de matemática. Ciclo de alfabetização.

\begin{abstract}
This article is a cutting of a more comprehensive $r$ Professor na Universidade Federal do Tocantins. Email: idemar@mail.uft.edu.bresearch whose objective was to verify the contributions of the National Pact for Literacy at the Right Age (PNAIC, in Portuguese) to the process of teaching and learning Mathematics in the literacy cycle of the Full-Time School Padre Josimo Morais Tavares, in Palmas, Tocantins, Brazil. This was a qualitative research, performed through semi-structured interviews conducted with a school supervisor, a PNAIC study advisor and literacy teachers who participated in PNAIC continued education. Classroom observations were also conducted in order to collect data. The results show that PNAIC formation provided meaningful contributions to the teaching practice, especially in connection to the use of different teaching methods, such as educational games and didactic sequences, in addition to breaking with the traditional assessment model.
\end{abstract}

\footnotetext{
${ }^{1}$ Doutor em Educação pela UFPR - Universidade Federal do Paraná (2006). Professor adjunto da Universidade Federal do Tocantins, professor e orientador nos Programas de Mestrados Acadêmico e Profissional em Educação na UFT, Palmas, TO, Brasil. Quadra 109 Norte, Avenida NS-15, ALCNO-14, Plano Diretor Norte | 77001-090| Palmas/TO. E-mail idemar@mail.uft.edu.br.

2 Mestre em Educação pela UFT - Universidade Federal do Tocantins (2018. Pedagoga Ulbra TO (2001). Professora Efetiva da Educação Básica da Rede Estadual de Ensino do Tocantins. É integrante da equipe de Orientadores Educacionais e formadores de professores do estado do Tocantins. Brasil. Praça dos Girassóis, s/n Plano Diretor Norte, Palmas - TO, 77003-910. E-mail seilapugas@ gmail.com.
} 
Keywords: PNAIC. Teaching of Mathematics. Literacy Cycle.

\section{INTRODUÇÃO}

Este artigo é parte de uma dissertação de mestrado cujo objeto de estudo foi a influência do Pacto Nacional Pela Alfabetização na Idade Certa (PNAIC) no processo de ensino e aprendizagem de matemática no ciclo de alfabetização. O PNAIC foi implantado no ano de 2012 por meio da portaria $\mathrm{n}^{\mathrm{o}} 867$, de 4 de julho de 2012, e contou com a adesão de 5.319 municípios. Apresenta-se como uma política pública que busca a garantia da qualidade do ensino às crianças matriculadas no $1^{\circ}, 2^{\circ}$ e $3^{\circ}$ ano do Ensino Fundamental. Trata-se de um compromisso assumido pelo governo federal, estados, munícipios e Distrito Federal, com o propósito de que todas as crianças sejam alfabetizadas em língua portuguesa, matemática e demais áreas do conhecimento, até os 8 anos de idade, ou seja, ao final do terceiro ano do Ensino Fundamental.

Durante muitos anos, o direito à educação consistia apenas em conferir à criança a oportunidade de estar matriculada em alguma instituição de ensino. A partir do aprofundamento dos estudos, percebeu-se que além de estar matriculada, era necessário criar condições para que a criança permanecesse nas unidades escolares e lhe fosse garantido o direito de aprender.

Embora se reconheça o quanto o Brasil avançou em direção à democratização do acesso e da permanência dos estudantes no Ensino Fundamental, uma vez que hoje 97\% das crianças estão na escola (LEIRAS, 2006), temos ainda desafios junto aos estudantes matriculados no ciclo de alfabetização, principalmente em relação aos processos de aquisição da leitura, da escrita e de conhecimentos matemáticos. Os dados da Avaliação Nacional da Alfabetização (ANA), realizada em 2016, indicam que cerca de 34\% dos estudantes brasileiros apresentavam proficiência insuficiente na escrita. De acordo com o MEC, o nível insuficiente indica que os estudantes não conseguem identificar a finalidade de um texto nem localizar informações explícitas. Com relação aos conhecimentos em matemática, 55\% dos estudantes brasileiros não resolvem, por exemplo, operações de subtração com dois algarismos.

A atenção do PNAIC considera que no período de alfabetização se faz necessário assegurar, a cada criança, o direito às aprendizagens básicas da apropriação da leitura, da escrita, da matemática e também a consolidação de saberes essenciais dessa apropriação; o desenvolvimento das diversas expressões; assim como a aprendizagem de outros saberes fundamentais das áreas e dos componentes curriculares obrigatórios. Nesse sentido, o PNAIC reconhece a necessidade de esforço por parte de alfabetizadores e alfabetizadoras, que precisam 
trabalhar em sintonia com ações efetivas da equipe gestora de cada unidade escolar (BRASIL, 2012). Além disso, os cadernos de formação do PNAIC deixam evidente que o processo de alfabetização matemática requer o constante diálogo com outras áreas do conhecimento e, principalmente, com as práticas sociais.

Tendo em vista os objetivos do PNAIC em relação à execução de mudanças efetivas no campo específico da alfabetização matemática, decidiu-se verificar junto a algumas professoras alfabetizadoras que participaram da formação do PNAIC como se materializaram em suas práticas a abordagem dada à metodologia de ensino e à avaliação das aprendizagens nos processos de ensino e aprendizagem da matemática no ciclo de alfabetização.

As narrativas das professoras alfabetizadoras nos ajudarão a compreender as contribuições do PNAIC para o processo de aprendizagem de matemática no ciclo de alfabetização na Escola Municipal de Tempo Integral Padre Josimo Morais Tavares, Palmas, TO.

\section{ASPECTOS METODOLÓGICOS}

O desenvolvimento da pesquisa se deu a partir de uma escuta nas falas de profissionais da educação da Rede Municipal de Ensino de Palmas, TO, que participaram da formação continuada do PNAIC. Trata-se de uma pesquisa de natureza qualitativa, cujo estudo consta de entrevistas semiestruturadas como um dos principais meios para o investigador produzir dados de pesquisa a partir das narrativas dos sujeitos da pesquisa e, ao mesmo tempo, valorizar a presença do investigador. As entrevistas semiestruturadas oferecem as perspectivas para que o informante disponha da liberdade e da espontaneidade necessárias para o enriquecimento da investigação. Realizamos entrevistas com sete profissionais: quatro professoras que exercem a docência em turmas de $1^{\circ}, 2^{\circ}$ e $3^{\circ}$ ano do Ensino Fundamental; uma coordenadora pedagógica da escola, a qual é responsável por subsidiar e auxiliar os professores dos anos iniciais; uma coordenadora municipal do PNAIC; e uma orientadora de estudos do PNAIC.

A escolha das professoras entrevistadas atendeu aos seguintes critérios: ser docente efetivo na Rede Municipal de Ensino; professor regente de $1^{\circ}$ ao $3^{\circ}$ ano com mais de três anos lotado na Rede Municipal; ter disponibilidade e demonstrar interesse em participar da pesquisa. A escolha dos componentes da equipe pedagógica se deu em função de esses profissionais serem os responsáveis diretos em subsidiar a materialização das ações didático-pedagógicas junto às professoras alfabetizadoras. Já a opção pela Escola de Tempo Integral Padre Josimo 
Morais Tavares se deu pelo fato de que essa unidade de ensino conta com doze classes que atendem crianças matriculadas no ciclo de alfabetização.

As entrevistas ancoraram-se em um roteiro abrangendo questões que tratam sobre a formação acadêmica e experiências na Educação Básica; a motivação para participar do PNAIC; a importância da formação continuada para professores e as contribuições do PNAIC para os processos de ensino-aprendizagem da matemática no ciclo de alfabetização. Tais questões também foram realizadas à equipe pedagógica e de formação do PNAIC.

$\mathrm{Na}$ intenção de preservar a identidade das participantes da pesquisa, elas foram designadas com nomes de frutos do cerrado tocantinense: Bacaba, Baru, Buriti, Caju, Mangaba, Murici e Pequi.

\section{CONSIDERAÇÕES SOBRE O PNAIC}

$\mathrm{Na}$ análise dos cadernos do PNAIC, observamos algumas modalidades organizativas para o desenvolvimento do ensino da matemática no ciclo de alfabetização, dentre as quais tiveram predomínio a resolução de problemas, o uso dos jogos e o desenvolvimento de sequências didáticas.

A "resolução de problemas" é contemplada na maioria dos cadernos do PNAIC e é considerada um dos aspectos centrais da Educação Matemática, desde o início da escolarização das crianças. O PNAIC define "problema" da seguinte maneira: "Um problema é uma situação que o indivíduo tem que enfrentar (resolver) por necessidade ou desejo, mas que apresenta algum nível de obstáculo que impede ser resolvido de imediato ou mecanicamente" (BRASIL, 2014, p. 12). Os problemas estão vinculados à necessidade de o sujeito resolver situações desafiadoras, o que requer análise e compreensão da situação/fenômeno em estudo. A utilização destes na educação requer metodologias de ensino que possibilitem ao estudante desenvolver o "espírito investigativo, crítico e criativo, no contexto de situações-problema, produzindo registros próprios e buscando diferentes estratégias de solução" (Ibidem, p. 12).

Os cadernos do PNAIC sinalizam, ainda, que o professor proponha problemas advindos preferencialmente da realidade das crianças.

\footnotetext{
O professor pode trazer questões relacionadas com a realidade dos estudantes: as altas taxas de desemprego (tão preocupantes no dia de hoje), a existência de diversos índices de variação de preço e suas composições (que tanto nos incomodam e que são alvo de discussões), as medições da popularidade do Presidente da República ou de uma política que está sendo implementada (a reforma da previdência ou a tributária, por exemplo), a matemática da rua ou a matemática presente no dia a dia do trabalho,
} 
e muitas outras disponíveis nos diversos meios de comunicação (JACOBINI, 1999, p. 42).

Esses exemplos de situações advindas da realidade social do estudante favorecem a reflexão crítica e a aplicação matemática numa situação-problema, o que certamente favorece ao professor que se investiguem e explorem contextos a partir do universo de seus estudantes, de sua cultura e experiências.

Por meio de jogos e as brincadeiras infantis, a criança entra em contato com as primeiras noções matemáticas de modo espontâneo.

O jogo é um recurso que visa a auxiliar o trabalho pedagógico e ampliar as potencialidades do uso da ludicidade no desenvolvimento dos conceitos, no desenvolvimento da capacidade de organização, análise, reflexão e argumentação, e ainda uma série de atitudes como: aprender a ganhar e a lidar com o perder, aprender a trabalhar em equipe, respeitar regras, entre outras (BRASIL, 2014, s/p.).

O jogo é um recurso que, se usado com uma intencionalidade pedagógica, pode auxiliar no desenvolvimento dos conceitos, favorecendo que a criança analise, reflita e argumente, podendo ainda desenvolver os conteúdos atitudinais. Pelo PNAIC, os jogos e as brincadeiras têm uma a dimensão educativa, e decorre da importância da ludicidade como recurso pedagógico que possibilita a integração e a interação entre as crianças, a promoção do prazer, e um meio para introduzir, aplicar e consolidar conceitos. “(...) a elaboração de problema, escrita pelo professor ou pelo estudante a partir do jogo, contribui para o desenvolvimento dos conceitos matemáticos” (BRASIL, 2014, p. 73).

O uso dos jogos precisa ser integrado a situações que levem ao exercício da análise e da reflexão. Propõe-se também a integração dos jogos com outras atividades e áreas e destaca-se a dimensão educativa do jogo, uma vez que esse recurso é um meio de garantir a realização de certas aprendizagens matemáticas, no contexto específico da escola.

Trabalhado de forma adequada, além dos conceitos, o jogo possibilita aos estudantes desenvolver a capacidade de organização, análise, reflexão e argumentação, uma série de atitudes como: aprender a ganhar e a lidar com o perder, aprender a trabalhar em equipe, respeitar regras, entre outras (BRASIL, 2014, p. 5).

Já as sequências didáticas (SD) devem ser desenvolvidas na perspectiva do ensino de conteúdos por meio de atividades sequenciadas e organizadas com objetivos bem definidos e esclarecidos para os professores e estudantes. As sequências didáticas contribuem para a aprendizagem e a construção de novos saberes, além de servir para a reflexão sobre a prática 
docente, por meio da observação do seu processo de desenvolvimento e da interação entre todos os envolvidos.

Zabala (1998, p. 18), define sequência didática (SD) como "um conjunto de atividades ordenadas, estruturadas e articuladas para a realização de certos objetivos educacionais, que têm um princípio e um fim conhecidos tanto pelo professor como pelos alunos". Para esse autor, a SD deve ser organizada de modo a considerar as três dimensões do processo de ensino e aprendizagem: conceituais, em que o professor precisa conhecer o espectro de conceitos subjacentes e que influenciam na compreensão do objeto em estudo; procedimentais, em que o professor precisa perceber e criar condições adequadas às necessidades específicas para cada estudante; e atitudinais, intimamente ligadas às ações formativas, não bastando propor debates e reflexões sobre comportamento cooperativo, tolerância, justiça, respeito mútuo, dentre outros, mas sim viver um clima de solidariedade, cooperação, tolerância e cumplicidade. Assim, a SD deve atender aspectos como: apresentação da situação; problemas ou questões; respostas intuitivas ou suposições; fontes de informação; busca de informação; elaboração de conclusões; generalização; exercícios de memorização; prova ou exame; avaliação.

A proposição do uso de SD pode servir para estimular discussões sobre a matemática e o cotidiano, bem como reflexões entre diferentes temas matemáticos e entre a matemática e outras áreas do conhecimento, visto que é possível estabelecer relações entre conceitos de matemática e das demais disciplinas escolares.

O PNAIC entende que a avaliação das aprendizagens ancora-se na LDB n.9394/96 e na Resolução n. ${ }^{\circ} 07$ de 2010 do Conselho Nacional da Educação Básica (CNE), artigo 32, a qual assume um caráter processual formativo e participativo, com vistas a assegurar a aprendizagem de qualidade a todas as crianças matriculadas no ciclo de alfabetização. Assim busca-se no ciclo de alfabetização a progressão continuada dos estudantes do $1^{\circ}$ para o $2^{\circ}$ ano e deste para o $3^{\circ}$ ano. O ciclo de alfabetização configura-se como uma proposta de encaminhamento do processo de ensino e de aprendizagem das crianças entre 6 e 8 anos, em uma perspectiva de continuidade e aprofundamento, visando a construção de um sistema educacional democrático, não seletivo e não excludente.

A proposta de avaliação do PNAIC procura potencializar a formação das crianças pela garantia da continuidade da aprendizagem na alfabetização, ao longo dos três anos, por meio de um acompanhamento qualitativo e da consideração do tempo de aprendizagem. Adota uma concepção progressiva e considera a avaliação como uma ação que inclui os vários sujeitos envolvidos nos processos de ensino e aprendizagem. Isso significa dizer que no PNAIC são 
avaliados os modos como as crianças se apropriam dos conhecimentos e também as maneiras que os profissionais utilizam para mediar os processos de ensino.

A proposta do PNAIC prima por uma avaliação formativa no ciclo de alfabetização, uma vez que tem como objetivo ampliar o tempo do processo de aprendizagem dos estudantes. Para tanto, no processo de avaliação das crianças é sugerido ao professor que pense nos instrumentos e estratégias que favoreçam a progressão continuada das crianças. Assim, o PNAIC defende que o planejamento pedagógico deve estar a serviço da inclusão. Ele deve ser usado como estratégia para garantir atendimento diferenciado para atender às especificidades de cada turma e qualificar o processo de aprendizagem de todos os estudantes.

A perspectiva do PNAIC se assemelha às ideias de Hoffman (1998). Para a pesquisadora, a prioridade da avaliação deve ser com a aprendizagem dos estudantes, portanto o compromisso do professor é com a aprendizagem. Hoffmann (1998) reconhece que avaliar e discutir sobre a avaliação da aprendizagem é algo complexo e desafiador. Considera que um dos grandes gargalos no processo de avaliação consiste no fato de o professor elaborar uma diversidade de estratégias pedagógicas e achar que todos os estudantes responderão de uma mesma forma, ou seja, o professor acredita que vai obter uma mesma resposta para a avaliação.

A pesquisadora pontua que é importante que nós, professores, cultivemos a consciência sobre a diversidade de estudantes que constituem uma sala de aula e da diversidade de respostas dadas pelos estudantes diante de um instrumento de avaliação, visto que cada indivíduo aprende sobre um objeto de conhecimento de uma forma própria, conforme suas experiências de vida e seu contexto social. Pelo PNAIC, a avaliação se dá nos diversos momentos em que ocorre o ensino e a aprendizagem, como nos jogos, nas brincadeiras e na realização de atividades direcionadas pelo professor.

\section{CONTRIBUIÇÕES DO PNAIC AO PROCESSO DE ENSINO E APRENDIZAGEM DE MATEMÁTICA}

Os excertos das narrativas das entrevistadas transcritos a seguir revelam como as formações do PNAIC foram importantes ao processo de formação, tanto em relação à compreensão de conceitos matemáticos como em relação aos processos de ensinar e aprender, os quais estão diretamente alicerçados em questões metodológicas e epistemológicas. Por respeito ao modo como se expressaram, as citações entre aspas não sofreram alterações gramaticais. Citam-se, para abrir esta discussão, as seguintes falas das entrevistadas: 
Aprendemos muito como diferenciar as aulas, principalmente os conteúdos [...] Para iniciar as dezenas, trabalhamos com o livro "Dez passos na areia (...) O PNAIC trouxe muito aprendizado para minha prática profissional... Como lidar com os conteúdos.... Às vezes um único conteúdo pode ser ministrado de diversas formas para o aluno. Eu trabalhei a subtração com o livro "Nunca conte com os ratinhos." Eu lia a história e eles iam fazendo a subtração (CAJU, 2017).

[...] nós trouxemos a balança da enfermagem, e a enfermeira da escola nos auxiliou no trabalho, ela vinha e pesava cada criança e a gente ia anotando no quadro o peso de cada criança. Também fez a fita métrica que foi fixada na parede.... Nesse momento a gente percebia a altura de cada criança (MANGABA, 2017).

[...] Ao participar de uma atividade em uma escola do campo, vivenciamos as crianças trabalhando os conteúdos de um modo diferente. [...] participando de uma feirinha... E às vezes algumas crianças passavam o troco errado para ver se o coleguinha percebia (PEQUI, 2017).

Às vezes um único conteúdo pode ser ministrado de diversas formas para os estudantes. E o PNAIC veio muito ajudar, colaborar e ensinar a melhorarmos nossa prática em sala de aula (BURITI, 2017).

[...] a gente vê contribuições do PNAIC, principalmente porque as professoras perceberam a importância de ver outros conteúdos, como grandezas e medidas, que antes eram esquecidos. [...], mas as professoras ainda se apegam a trabalhar com o livro didático (MURICI, 2017).

Os recortes dessas falas nos dão indicativos de que as professoras têm disposição para novas aprendizagens e reflexão crítica sobre o fazer docente. Esses aspectos são elementos constitutivos da compreensão da prática docente, uma vez que refletem a ideia freireana: "Ensino porque busco, porque indaguei, porque indago e me indago" (FREIRE, 1996, p. 14). Durante o processo de ensinar e aprender, é essencial que nós, professores, tenhamos a disponibilidade para rever o nosso fazer didático-pedagógico, e é essa atitude que as educadoras entrevistadas manifestam.

Certamente, o uso da literatura infantil pela professora Caju mostra que ela utilizou desses recursos para estabelecer conexões entre a matemática e a língua materna, bem como para ampliar a proposição de atividades interdisciplinares. Quanto à literatura infantil, Smole, Cândido e Stancanelli (1999) pontuam que esta pode ser usada como estímulo para ouvir, ler, pensar e escrever sobre a matemática.

A fala de Murici, em que se contrasta apegar-se ao livro didático a ver conteúdos diferentes, 'antes esquecidos', é extremamente reveladora. Ela evidencia uma dificuldade de muitos professores, que é estabelecer um equilíbrio no uso do livro didático, principalmente quando o foco do livro é apenas a transmissão de conceitos.

Zabala (1998) defende que o professor deve instigar os estudantes a trabalhar um conteúdo de modo a promover a formação integral dos sujeitos. Desse modo os conteúdos conceituais, embora abstratos, demandam compreensão, reflexão, análise e comparação. No 
PNAIC esses conteúdos estão estruturados em blocos e designados pelo termo "eixos estruturantes": número e operações; pensamento algébrico; geometria; grandezas e medidas; tratamento da informação. Esse bloco de conhecimentos é considerado a base pela qual as crianças matriculadas nos três anos iniciais de escolarização constroem o pensamento matemático.

Os conteúdos procedimentais requerem diferentes ações, como a construção de uma maquete, a dramatização, a confecção de um jogo pedagógico para representar o sistema decimal, dentre outros. Nesse processo de aprendizado, é notório o uso do corpo, da memória, do intelecto, da dedução e da habilidade motora, dentre outras especificidades. Os conteúdos procedimentais envolvem ações ordenadas com um fim, ou seja, direcionadas para a realização de um objetivo, aquilo que se aprende a fazer fazendo, como saltar, escrever com letra cursiva, desenhar, cozinhar, dirigir etc. Podem ser chamados de regras, técnicas, métodos, destrezas ou habilidades.

O conteúdo atitudinal tem a ver com a aprendizagem de normas e valores para uma melhor convivência em sociedade. No meio escolar, esses conteúdos são trabalhados continuamente pelas crianças em atividades individuais e em grupo. Como exemplo, podemos citar os jogos, as brincadeiras livres e direcionadas, as dramatizações que fomentam boas atitudes diante do próximo e de situações inusitadas, dentre outros.

Os cadernos do PNAIC dão atenção a uma proposta de ensino voltada para a integração de conteúdos conceituais, procedimentais e atitudinais, embora uma ausculta nos fazeres de sala de aula reverbere a predominância do foco nos conteúdos conceituais em relação aos demais. Esses cadernos também defendem uma mudança de postura do professor em relação à gestão e organização dos espaços de sala de aula, atentando-se para o uso de metodologias que colocam os estudantes como agentes ativos no processo de construção do saber.

A maioria das entrevistadas reconhece que houve contribuições significativas do PNAIC para o desenvolvimento dos conteúdos matemáticos, mas ainda há um forte apego ao uso de livros didáticos, bem como ao currículo exigido pelo Estado. Entre os fatores que corroboram para que as professoras citem e deem primazia aos conceitos podem estar questões de ordem burocrática, como cumprir conteúdos prescritos nos livros didáticos e preparar as crianças para avaliações de larga escala (como ANA e SAEB); o distanciamento entre a formação das professoras dos anos iniciais e os currículos da escola; e a concepção hegemônica de educação, que concebe o conhecimento como sendo constituído de informações e de fatos a serem transferidos para o estudante. 
Essa concepção hegemônica de educação, em que se dá primazia aos conceitos, associase com o que Paulo Freire (1996) chamou de "educação bancária", em que o conhecimento se confunde com o ato de um depósito bancário. Contudo, reconhecemos que os conteúdos escolares deverão promover a problematização, o que significa dizer que os conteúdos de um currículo devem ser discutidos criticamente por todos os envolvidos, de acordo com a relevância social do problema, sua aplicabilidade, os interesses e as necessidades reais dos estudantes.

Esse panorama nos conduz aos estudos de Skovsmose (2001) sobre a educação matemática crítica, nos quais o autor apresenta uma reflexão sobre o papel da matemática escolar, considerando as demandas sociais atuais. Caracteriza a educação crítica como aquela em que os professores e os estudantes se envolvem conjuntamente no processo educacional por meio do diálogo, de forma a desenvolver a democratização do saber. A partir da perspectiva teórica do pesquisador, inferimos que o conteúdo de um currículo escolar deve partir das demandas sociais, da relevância, da aplicação, dos interesses e das necessidades reais dos estudantes. Além disso, o autor coloca em pauta uma série de discussões relativas ao papel sociopolítico da educação matemática, questionando o modelo "tradicional" do ensino de matemática, que deliberadamente contribui para uma cultura de obediência e submissão.

Skovsmose (2001) propõe um currículo baseado na incerteza, no questionamento a respeito de possíveis interesses envolvidos na escolha dos modelos, não aceitando a neutralidade da matemática e suas soluções infalíveis. Decerto, o fato de as professoras trabalharem a partir de um conjunto de conhecimentos selecionados previamente (pelo Governo Federal e seus respectivos entes) talvez seja um dos empecilhos para a promoção de uma alfabetização que considere os conhecimentos prévios das crianças e os relacione com os problemas sociais existentes, ação que, apesar de estar se esboçando timidamente - segundo as narrativas das alfabetizadoras pesquisadas -, ainda não se efetivou plenamente devido à excessiva preocupação com o livro didático e com a utilização de um currículo previamente aprovado.

A maioria das profissionais, ao abordar as contribuições do PNAIC em matemática, destaca como ponto comum a alusão aos jogos pedagógicos desenvolvidos pela formação e as sequências didáticas. Houve também a menção ao uso dos livros literários. A professora Bacaba, por exemplo, declarou que o PNAIC colaborou para o desenvolvimento dos jogos em salas com grande quantidade de crianças. Ela citou também a confecção de jogos: “Aprendi no PNAIC como trabalhar mais com o lúdico, principalmente com a sala lotada, que é o que temos 
todos os anos!" E finaliza esclarecendo que confecciona os jogos para que esses auxiliem na aprendizagem das crianças.

Os jogos oportunizaram outras formas de trabalhar com a matemática, com o uso, por exemplo, da Caixa de Matemática:

Nós trabalhamos muito os jogos, que é aquela caixinha amarela, que as crianças tanto amam (...) A gente teve que reproduzir um pouco de material pra que fosse possível atender maior quantidade de crianças, haja visto que em um jogo não atendia todas as crianças ao mesmo tempo. Aí nós tivemos a preocupação de reproduzir alguns jogos para que atendesse todas as crianças (MANGABA, 2017).

A professora Baru (2017) destaca que o lúdico é um dos principais aspectos em que o PNAIC veio a colaborar com o seu fazer, especialmente em suas experiências com as crianças no período da transição da Educação Infantil para o Fundamental. Antes, ela não reconhecia a importância do brincar. Mas seu discurso demonstra uma mudança de ponto de vista e de atitude: "[...] tem que brincar sim e a ludicidade foi a coisa mais importante para mim não só na língua portuguesa nem matemática, em todas as disciplinas”.

Ela prossegue com relatos que revelam como era seu conceito antes do PNAIC, em que brincar durante as suas aulas era visto como algo inviável, uma vez que a escola era lugar de aprender.

Hoje depois do PNAIC olho para trás envergonhada quando fazíamos isso. Eu fazia isso e hoje eu me envergonho. Meu Deus, como a gente faz coisa errada quando não conhece! São ainda crianças e criança tem que brincar sim e a ludicidade foi a coisa mais importante para mim não na língua portuguesa nem matemática, em todas as disciplinas (BARU, 2017).

A professora explica que, à medida que ia participando das formações, suas concepções sobre o uso do lúdico foram ampliando, o que a levou a mudar as suas práticas e a incluir jogos para trabalhar determinados conteúdos.

Nas narrativas da professora Pequi (2017), pode-se observar que, embora ela também tenha feito menção ao jogo, usou o termo "recursos visuais". Quando perguntamos sobre como esses jogos poderiam colaborar com as práticas de ensino e aprendizagem da matemática, ela afirmou:

[...] sim, eu acredito que sim, que essas ações no âmbito da matemática têm trazido um grande ganho para a gente por que são recursos visuais que são confeccionados nessas formações e a utilização deles na escola a gente percebe que o aluno tem aprendido com mais facilidade [...] (PEQUI, 2017).

Ao se referir ao termo "recursos visuais", está falando dos jogos e também de outros materiais e atividades que auxiliam na realização das atividades: 
No ano de 2015 a gente esteve presente em algumas unidades acompanhando o desenvolvimento dessas práticas em algumas ações junto com os formadores, e a gente percebia a empolgação das crianças e de como elas estavam aprendendo. Então eu acredito que as orientações e as atividades desenvolvidas no ano da matemática trouxe bastante aprendizado e de forma gostosa (PEQUI, 2017).

Nas narrativas da professora Murici (2017), pudemos observar que, embora ela também tenha feito menção positiva à importância dos jogos nos processos formativos, pondera que a metodologia com o uso dos jogos na escola é ainda incipiente.

Durante as formações do PNAIC, foram desenvolvidos vários jogos para trabalhar com as crianças aqui da escola, mas eu percebo que esse uso é muito limitado e é restrito a alguns professores; uns utilizam de vez em quando, outros não (MURICI, 2017).

A professora sugere a necessidade de utilizar jogos para articular tanto as práticas da matemática como as das demais disciplinas: “O uso de jogos deve ser ampliado não só à matemática, como a outras disciplinas", afirma Murici.

As professoras Caju e Buriti esclareceram que o PNAIC favoreceu a compreensão quanto ao uso dos jogos com uma intencionalidade pedagógica:

[...] Eles gostaram muito do "Boca do palhaço", nós desenvolvemos na sala para trabalhar o sistema monetário, troco, dinheiro, valores, a gente fazia uma sequência, eles gostaram muito, gostaram também de fazer o "Ganha cem" que eles vão juntando até chegar a uma centena, isso a gente introduzia sempre... eu costumo usar para introduzir alguma coisa que eu estou usando (CAJU, 2017).

Um dos jogos que utilizamos foi "Dado Numeral". Ao invés do dado com as bolinhas, usamos números onde a criança deveria usar da adição ou subtração para chegar ao resultado final. Assim um aluno estaria com 1 dado, outro aluno com segundo dado e um terceiro aluno deveria falar o valor que cada aluno colocou. [...] também tivemos o "Jogo da Argola", nesse os estudantes deveriam esconder algumas argolas e nisso ele utilizaria apenas da subtração onde receberia um valor e daquele valor tirasse e escondia, daí o outro aluno tinha de saber quanto que foi tirado daquelas argolas (BURITI, 2017).

As narrativas das professoras Caju e Buriti deixaram explícito o uso dos jogos como mobilizadores da aprendizagem, nesse caso associada à compreensão do sistema monetário, do sistema de numeração decimal e das operações aritméticas, a partir da utilização dos jogos "Boca do Palhaço", "Ganha Cem", "Dado Numeral" e "Jogo da Argola".

Moretti e Souza (2015) pontuam que o jogo ou brincadeira pode constituir-se como importante recurso metodológico nos processos de ensino-aprendizagem. Para tanto, o mesmo deve ser planejado de modo intencional e em relação com o conceito que se pretende ensinar. Em relação aos jogos para trabalhar os conceitos matemáticos, as pesquisadoras sinalizam que 
ao planejar é importante que o professor saiba a finalidade do jogo, de modo a fazer as mediações que favorecem a aprendizagem dos estudantes.

A professora Bacaba (2017) destaca a importância de se confeccionar materiais para desenvolver atividades mais dinâmicas, inclusive a sua fala traz indícios de que as crianças gostam de aprender com o uso das atividades lúdicas. Mas ela deixa transparecer que o uso dos jogos pode acarretar conflitos, e talvez isso se dê devido à quantidade de crianças na sala de aula.

As narrativas das professoras nos levam a inferir que essas profissionais reconhecem que o PNAIC as auxiliou na utilização de jogos em suas aulas, já que cumpriu o papel de auxiliar no ensino do conteúdo e propiciou a aquisição de diversas habilidades, além de permitir o desenvolvimento do raciocínio operatório do sujeito (MOURA, 1992).

Em relação ao uso de sequências didáticas, as falas das professoras dão indícios de que estas possibilitaram a elaboração de planejamentos para ensinar um conteúdo e organizar as atividades de acordo com os objetivos que se quer alcançar. Bacaba, Buriti e Caju esclareceram que o PNAIC favoreceu a compreensão e o uso das sequências didáticas: “[...] A sequência didática foi algo que eu aprendi no PNAIC e eles gostam muito de uma maneira de diferenciar as aulas” (BACABA, 2017). “[...] trabalhamos a sequência didática, usamos o Quadro Valor Lugar (QVL) e os estudantes amaram, porque foram eles que confeccionaram o material [...] utilizando a matemática onde eles poderiam desenvolver as continhas!” (BURITI, 2017). "Eu aprendi o que é a sequência didática e como desenvolvê-la com as crianças" (CAJU, 2017).

Os relatos de Buriti (2017) informam que anteriormente ela apresentava dificuldades em trabalhar com SD. A professora destaca o fato de nunca ter aprendido a organizar uma sequência didática.

[...] Me recordo bem quando a orientadora [do PNAIC] fez um trabalho conosco onde tínhamos de fazer uma sequência didática, e até então eu não havia aplicado uma sequência didática na minha aula, e isso pra mim foi de um aprofundamento muito grande porque eu vi que na sequência didática eu não tenho que trabalhar a matemática só na matemática, eu posso aplicar matemática na ciências, no português ou geografia aprofundando o que está sendo passado na matemática e concretizar em outras disciplinas dando uma continuidade (BURITI, 2017).

A professora ainda destaca o fato de que uma mesma sequência didática pode ser utilizada para trabalhar diferentes disciplinas, o que permite a integração entre as áreas do conhecimento e a continuidade daquilo que é proposto para as crianças.

Guimarães e Giordan (2011, p. 11) pontuam sobre o desenvolvimento de sequência didática em sala de aula: 
É um passo fundamental para a análise do alcance educacional da proposta de ensino [...] momento em que a ação ensino-aprendizagem efetivamente se processa e os objetivos de ensino que mobilizam a incorporação dessas estratégias se consolidam. Nessa fase é essencial que se retorne ao início e reveja a elaboração da Sequência Didática, não apenas para melhorar sua estrutura, mas principalmente a fim de reelaborar saberes profissionais do professor na construção e aplicação de estratégias de ensino.

Corroboramos com o uso da SD como um recurso pedagógico para o ensino da matemática (e demais disciplinas), pois esta permite um novo olhar sobre a organização curricular, com ênfase pautada em investigação, o que certamente favorece a problematização que leva o estudante a conferir o seu conhecimento prévio com o conhecimento apresentado no espaço de aprendizagem, levando-o a se apropriar de novos significados, novos métodos de investigação e a produzir novos produtos e processos. Além disso, o uso de SD possibilita trabalhar as três categorias de conteúdo: atitudinais, conceituais e procedimentais.

Além do uso da $\mathrm{SD}$, foram mencionados também os projetos didáticos como outra modalidade organizativa que auxilia as crianças nos processos de alfabetização. Projeto didático é uma investigação em profundidade de um assunto sobre o qual vale a pena aprender. A principal característica de um projeto é que há um esforço de pesquisa deliberadamente centrado em encontrar respostas levantadas pelas crianças e pelo professor.

Mangaba narra ter realizado um projeto intitulado "Animais de A a Z". A professora afirma que o projeto foi demandado do questionamento das crianças: "Como é que na escola tem peixe se não há rio?”. Esse projeto foi citado também por Murici (2017):

[...] a pergunta das crianças nos levou a pensar um modo de realizar um projeto que pudesse ampliar os conhecimentos delas [...] daí começamos com uma visitação no tanque de peixes na escola, [...] ampliamos as atividades, e os resultados foram apresentados na Feira de Ciências da escola (MANGABA, 2017).

[...] O PNAIC auxiliou no desenvolvimento de projetos, nós tivemos alguns projetos desenvolvidos pelos professores em relação aos animais tivemos dois projetos que foram apresentados na feira: Projeto "Animais de A à Z" e Projeto "Que bicho é esse" [...] então com esses projetos foi trabalhado o letramento, a matemática, a ciência e a história (MURICI, 2017).

As narrativas evidenciam que o PNAIC apresentou aos participantes das formações várias possibilidades metodológicas, contribuindo para a percepção de uso de materiais, nas distintas disciplinas, bem como nos modos de organização da sala de aula, elementos a que até então muitos professores não se atentavam no seu fazer docente. Nessa perspectiva, Bacaba afirma: “[...] tive de rever muito minha forma de dar aula e da organização da sala de aula, algo que eu não levava em consideração e que faz muita diferença durante a aula”. A professora em sua narrativa aponta que o conhecimento adquirido durante a formação do PNAIC fez diferença 
no seu trabalho e agregou novas compreensões sobre o modo de trabalhar com as crianças e os modos de organização da sala de aula.

Compreendemos a avaliação da aprendizagem como um processo em que se observa a aprendizagem que ocorre em todo o desenvolvimento do estudante como ser humano, identificando as dificuldades individuais e da classe, de modo a auxiliar o professor na elaboração do planejamento, na eleição dos conteúdos e na revisão de metodologias. Bacaba mencionou que o PNAIC trouxe ressignificação sobre os modos de avaliar as crianças: "Antes eu considerava somente erros e acertos das crianças [...] depois avançamos e agora vejo a avaliação para além da nota."

O excerto da fala revela mudança em relação às finalidades da avaliação, ao pontuar a necessidade de um fazer pedagógico em que a avaliação está para além da nota. Ela relata também a realização de avaliações bimestrais, ocasião em que retoma todas as atividades anteriormente trabalhadas: "[...] Busco sempre fazer uma retomada daquilo que trabalhamos, para ver quais habilidades preciso retomar."

Um dos aspectos pontuados por Baru (2017) foi a ampliação do olhar quanto aos tempos de aprendizagem das crianças:

[...] antes eu não dava muita atenção aos modos como a criança aprendia [...] O fato mais importante foi olhar para a criança e ver que a criança tem seu tempo e que ela vai aprender no seu tempo e que não tem aquela coisa que veio lá da educação infantil e que agora no Ensino Fundamental não é mais brincadeira.

A professora Baru demonstrou a necessidade de verificar as especificidades da faixa etária das crianças. Desse modo, ela busca respeitar e diferenciar os tempos de aprendizagem dos estudantes.

Buriti (2017) se reporta aos instrumentos e critérios para avaliar os estudantes: "Podemos avaliar de modos diferentes; na geometria podemos trabalhar o material concreto, tampinhas, garrafas.” Por outro lado, Pequi atribuiu ao PNAIC contribuições especificamente quanto à melhoria dos resultados no SAEP.

[...] foi alcançando uma abrangência enorme e a gente tem visto resultado disso aí nas avaliações, como do SAEP que são aplicadas na Rede, e os resultados nacionais também que são resultados dessa prática desenvolvida na formação e assim eu acredito que esse resultado tem sido visível e hoje tem sido reconhecido mais na rede.

Pequi (2017) traz indícios de que o PNAIC favoreceu a compreensão sobre diagnóstico, monitoramento e propostas de intervenção em toda a rede municipal de ensino: 
[...] eu sempre acompanhei todas as turmas no sentido de estar dando suporte na questão de acompanhar por exemplo as dificuldades dos professores nas turmas né e questionamentos, e a gente esteve mais presente nas formações do GTAL né, que foi agora no ano de 2016 e nesse acompanhamento fez um diagnóstico de como a escola estava, de como era as atividades e construir junto com eles a estratégia de como buscar solução pra essas dificuldades, então esse acompanhamento foi feito e tive oportunidade de estar em 7 em 2016.

Notório é na fala de Pequi (2017) os modos de avaliar. A alfabetizadora mostra a importância do diagnóstico do monitoramento dos professores e da escola, para redimensionar as ações escolares. O exemplo dado pela professora foi o GTAL (Grupo de Trabalho de Alfabetização e Letramento), que buscou construir estratégias para solucionar ou minimizar dificuldades pertinentes à alfabetização das crianças.

Murici (2017) nos dá pistas de como se procede a avaliação na escola.

\begin{abstract}
Vai ser uma aprovação... é $3^{\circ}$ ano não vai ter praticamente nenhuma reprovação. Nós tivemos o quê, duas estratégias nos $3^{\circ}$ anos que é: a primeira estratégia é essa do reforço. Então nós tivemos o reforço com eles da parte do Mais Educação, então os monitores do Mais Educação a gente teve esse reforço. E nós tivemos o reforço especial, eu digo especial porque foi uma estratégia para esse ano, a professora do $3^{\circ}$ ano ficou com uma turma dessas turmas mais selecionadas mas ela ficou com menos aulas - nós tínhamos outra professora contrato que dava o suporte pra ela, quando ela professora "dona da turma" pegava os estudantes com dificuldades dela e levava pro reforço ela mesma que já conhecia as dificuldades do aluno. A outra professora (que é uma professora muito competente, ela é contrato, mas, é um contrato com uma competência extrema, muito boa) ela ficava com a turma - com os demais estudantes trabalhando todo o conteúdo enquanto os outros estavam trabalhando esse conteúdo de forma diferenciada. Então uma professora que vê o aluno como um todo ela trabalha desde a dificuldade pedagógica do aluno - cognitiva, até as dificuldades sociais que ele encontra na família. Então ela faz um geral para estar resgatando a autoestima do aluno, pra estar mostrando pra ele a necessidade e a importância do estudo, pra estar trabalhando que se ele não aprende aqui ele vai ter um prejuízo dos demais anos seguintes.
\end{abstract}

Essa fala nos leva a inferir que a escola utiliza uma diversidade de estratégias para avaliar as crianças, como o monitoramento realizado pelas professoras, a promoção das aulas diferenciadas pelos monitores do Programa Mais Educação e a organização das crianças por níveis de aprendizagem.

Entre outros aspectos, as narrativas das alfabetizadoras evidenciam que, com o auxílio do PNAIC, elas estão rompendo com a ideologia da certeza e avaliando os alunos com base não apenas em respostas certas e erradas, mas valorizando os processos de pensamento e as estratégias dos estudantes. O absolutismo do "certo e errado" tem dado lugar à discussão, ao diálogo. Assim, as alfabetizadoras têm buscado analisar aquilo que, a princípio, parece um "erro da parte deles", mas que se trata de "um saber que o aluno possui, construído de alguma forma, [...] levando o estudante a um questionamento sobre suas respostas" (CURY, 2007, p. 80). 


\section{APONTAMENTOS FINAIS}

Buscamos dar voz às profissionais da educação sobre as contribuições do PNAIC ao ensino da matemática, especialmente em se tratando da metodologia de ensino e da avaliação da aprendizagem. As narrativas nos levam a concluir que o PNAIC trouxe grandes contribuições em relação ao processo de ensino e aprendizagem de matemática, especialmente no ciclo de alfabetização. Certamente isso se dá porque essas professoras entendem que a docência requer a troca de conhecimento entre os pares e a "atualização" dos saberes, o que explica o consenso, entre as entrevistadas, sobre a importância da formação continuada de professores para a sua profissionalização, com vistas a atender às especificidades educacionais requeridas para se trabalhar a matemática nos anos iniciais de escolarização.

As narrativas demonstram que o PNAIC favoreceu mudanças nas práticas pedagógicas relacionadas e isso se deu especialmente em relação aos modos da organização e gestão pedagógica em sala de aula, onde se incluiu o uso da caixa de matemática, de instrumentos como relógios de parede e o uso de jogos pedagógicos.

Os resultados apontaram para a autoavaliação e recontextualização de práticas pedagógicas de sala de aula, sendo que as profissionais externaram que a formação do PNAIC permitiu que elas vivenciassem práticas metodológicas de outros colegas e que essas práticas as ajudaram a rever suas concepções de como trabalhar a Matemática. A melhoria da prática docente foi representada pela influência do PNAIC na continuidade da docência e na utilização, produção e criação de materiais, especialmente os jogos, além do esclarecimento de conceitos e da elaboração das sequências didáticas.

O olhar de algumas alfabetizadoras sobre a função da avaliação da aprendizagem também foi modificado, resultando em um tratamento humanizado às crianças. Todos esses exemplos comprovam a importância do PNAIC no processo de ensino de Matemática e nos levam a presumir que a formação continuada de professores e alfabetizadores é essencial para o crescimento profissional dos professores.

\section{REFER̂̂ENCIAS}

BRASIL. Secretaria de Educação Básica. Diretoria de Apoio à Gestão Educacional. Pacto Nacional pela Alfabetização na Idade Certa: Apresentação. Ministério da Educação, Secretaria de Educação Básica, Diretoria de Apoio à Gestão Educacional. Brasília: MEC, SEB, 2014. $72 \mathrm{p}$. 
Ministério da Educação. Instituto Nacional de Estudos e Pesquisas Educacionais Anísio Teixeira. Indicadores da Avaliação Nacional da Alfabetização (ANA). Brasília: MEC/INEP, 2016.

CURY, H. N. Análise de erros: o que podemos aprender com as respostas dos alunos. Belo Horizonte: Autêntica, 2007.

FREIRE, P. Pedagogia da autonomia: saberes necessários à prática educativa. São Paulo: Paz e Terra, 1996.

GUIMARÃES, Y. A. F.; GIORDAN, M. Instrumento para construção e validação de sequências didáticas em um curso a distância de formação continuada de professores. 2011. Disponível em: <http://www.lapeq.fe.usp.br/textos/fp/fppdf/guimaraes_giordan-enpec2012.pdf>. Acesso em: 15 nov. 2019.

HOFFMANN, J. M. L. Avaliação, mito \& desafio: uma perspectiva construtivista. Porto Alegre: Mediação, 1998.

JACOBINI, O. A modelação matemática aplicada no ensino de Estatística em cursos de graduação. 1999. 155 f. Dissertação (Mestrado) - Instituto de Geociências e Ciências Exatas, Universidade Estadual Paulista, Rio Claro, 1999.

LEIRAS, D. IBGE: escolarização de crianças e adolescentes teve ligeiro aumento na última década. 22 de março de 2006. Globo on-line. São Paulo, 2006. Disponível em: $<$ https://oglobo.globo.com/sociedade/educacao/ibge-escolarizacao-de-criancas-adolescentesteve-ligeiro-aumento-na-ultima-decada-4594020>. Acesso em: 15 dez. 2019.

MORETTI, V. D.; SOUZA, N. M. M. Educação Matemática nos anos iniciais do Ensino Fundamental: princípios e práticas pedagógicas. São Paulo: Cortez, 2015.

MOURA, M. O. O jogo e a construção do conhecimento matemático. São Paulo: FDE, 1992.

SKOVSMOSE, O. Educação Matemática Crítica: a questão da democracia. Campinas: Papirus, 2001.

SMOLE, K. C. S.; CÂNDIDO, P. T.; STANCANELLI, R. Matemática e Literatura Infantil. 4. ed. Belo Horizonte: Editora Lê, 1999.

ZABALA, A. A prática educativa: como ensinar e aprender. Porto Alegre: Artmed, 1998.

Submetido em: 07 de janeiro de 2020 .

Aprovado em: 13 de março de 2020. 